\title{
Microwave-assisted fast and efficient synthesis of some crown ethers
}

\author{
Ahmad Ziafati, Hossein Eshghi*, Omolbanin Sabzevari \\ Department of Chemistry, Ferdowsi University of Mashhad, P.O. Box 91775-1436, Mashhad, Iran
}

Received 17 December 2008

\begin{abstract}
13-Crown-4, 16-crown-5, dibenzo-12-crown-4 and dibenzo-14-crown-4 were synthesized by a one-pot microwave-assisted procedure in good yields. Irradiation of diols and dichlorides in the presence of sodium hydroxide in DMSO gave title crown ethers presumably within a template effect.
\end{abstract}

(C) 2009 Hossein Eshghi. Published by Elsevier B.V. on behalf of Chinese Chemical Society. All rights reserved.

Keywords: Crown ether; Microwave irradiation; Template effect

The crown ethers are very attractive compounds for selective metal ion complexing agents [1,2], ion selective electrodes preparation [3-7] as well as in biological membranes [8] and pharmaceutical applications [9]. Moreover, crown ethers were usually phase transfer catalyst, now they are actual catalyst in organic reactions due to the selective interaction with neutral molecules [10,11].

Although a variety of methods for preparing of functionalized crown ethers are known [12-15], examples using such techniques (high dilution, fast addition, and template effect) to synthesize of unsubstituted crown ethers are relatively rare. Only a few syntheses of unsubstituted crown ethers have appeared in the literature [16-18], which were carried out according to Pederson's procedure [19]. For example, dibenzo-14-crown-4 was produced in $27 \%$ yield by a two-step reaction, whereas, one-pot treatment of catechol and 1,3-dibromopropane gave an undesired product in $11 \%$ yield [19]. Inoue and coworkers [17] prepared 16-crown-5 by reaction of 1,3-propandiol with oligoethylene glycol ditosylate or dichloride in $29 \%$ or $14 \%$ yields, respectively. Microwave-assisted organic chemistry is a relatively new technology that has been shown to significantly improve productivity in the rapid generation of complex molecules [20]. In this paper, we describe a rapid synthetic method for crown ethers (6-9) by microwave irradiation according to Scheme 1.

\section{Experimental}

All materials and solvents were purchased from Merck and Fluka. Melting points were determined in open capillary tubes in an Electrothermal IA 9700 melting point apparatus. ${ }^{1} \mathrm{H}$ NMR spectra were recorded on a

\footnotetext{
* Corresponding author.

E-mail address: heshghi@ferdowsi.um.ac.ir (H. Eshghi).
} 


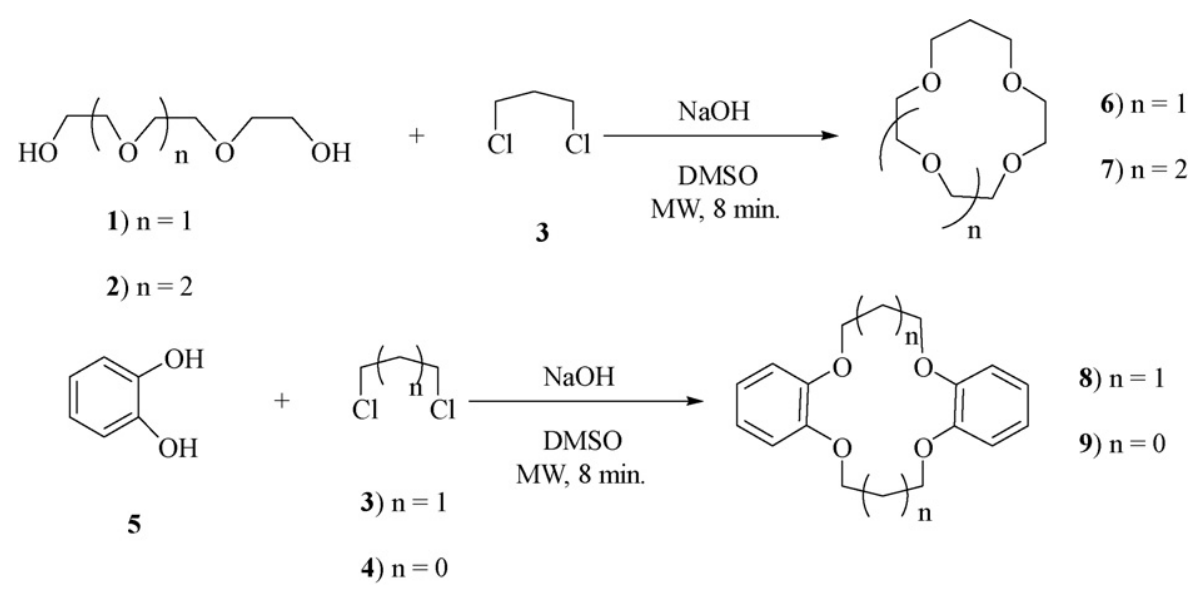

Scheme 1.

Bruker-100 MHz instrument using tetramethylsilane (TMS) as an internal standard. IR spectra were recorded on a Shimadzu-IR 470 spectrophotometer. The mass spectra were scanned on a Varian Mat CH-7 instrument at $70 \mathrm{eV}$. Irradiation was carried out in a domestic microwave oven (Electra, $2450 \mathrm{MHz}, 700 \mathrm{~W}$ ) for optimized time.

\subsection{General procedure for synthesis of crown ethers (6-9)}

A finely mixed diol $(10 \mathrm{mmol})$, alkyl dichloride $(10 \mathrm{mmol})$, and sodium hydroxide $(0.8 \mathrm{~g}, 20 \mathrm{mmol})$ in DMSO $(2 \mathrm{~mL})$ was irradiated in a microwave oven at $700 \mathrm{~W}$ for $8 \mathrm{~min}$. The reaction temperature was raised to $95{ }^{\circ} \mathrm{C}$ in the course of the reaction. After the reaction was completed (TLC), the reaction mixture was cooled, treated with concentrated $\mathrm{HCl}(5 \mathrm{~mL})$, and extracted with dichloromethane $(2 \times 20 \mathrm{~mL})$. The organic layer was washed with water $(10 \mathrm{~mL})$, dried over anhydrous $\mathrm{MgSO}_{4}$ and evaporated. The final crude product was purified by vacuum distillation or recrystallization from $n$-heptane.

13-Crown-4 (6): $72 \%$ yield; colorless oil, b.p. $169^{\circ} \mathrm{C}$ at $25 \mathrm{mmHg}$, lit. [21] 80-105 ${ }^{\circ} \mathrm{C}$ at $0.8 \mathrm{mmHg}$; IR (KBr): 2920, 2860, 1450, 1360, 1120, $940 \mathrm{~cm}^{-1} .{ }^{1} \mathrm{H} \mathrm{NMR}\left(\mathrm{CDCl}_{3}, 100 \mathrm{MHz}, \delta \mathrm{ppm}\right): 1.70$ (quintet, $\left.2 \mathrm{H}, \mathrm{CH}_{2}\right), 3.60(\mathrm{~m}, 16 \mathrm{H}$, $\left.\mathrm{CH}_{2} \mathrm{O}\right)$. MS $(\mathrm{m} / \mathrm{z}): 190\left(\mathrm{M}^{+}\right), 189,162,146,123,108,95,80,74$.

16-Crown-5 (7): $68 \%$ yield; colorless oil, b.p. $178{ }^{\circ} \mathrm{C}$ at $25 \mathrm{mmHg}$, lit. [17] 104-108 ${ }^{\circ} \mathrm{C}$ at $0.18 \mathrm{mmHg}$; IR (KBr): 2950, 2850, 1450, 1350, 1120, $950 \mathrm{~cm}^{-1}$. ${ }^{1} \mathrm{H}$ NMR $\left(\mathrm{CDCl}_{3}, 100 \mathrm{MHz}, \delta \mathrm{ppm}\right): 1.80$ (quintet, $\left.2 \mathrm{H}, \mathrm{CH}_{2}\right), 3.65(\mathrm{~m}, 20 \mathrm{H}$, $\left.\mathrm{CH}_{2} \mathrm{O}\right)$. MS (m/z): $234\left(\mathrm{M}^{+}\right), 230,222,202,195,184,175,160,151,143,121,110,86$.

Dibenzo-14-crown-4 (8): $70 \%$ yield; white solids; m.p. $=152-153{ }^{\circ} \mathrm{C}$, lit. [19] 150-152 ${ }^{\circ} \mathrm{C}$; IR (KBr): 3000, 2950 , 2850, 1600, 1450, 1300, $900 \mathrm{~cm}^{-1} .{ }^{1} \mathrm{H} \mathrm{NMR}\left(\mathrm{CDCl}_{3}, 100 \mathrm{MHz}, \delta \mathrm{ppm}\right): 2.25$ (quintet, $\left.4 \mathrm{H}, J=8.0 \mathrm{~Hz}, \mathrm{CH}_{2}\right), 4.25(\mathrm{t}$, $\left.8 \mathrm{H}, J=8.0 \mathrm{~Hz}, \mathrm{CH}_{2} \mathrm{O}\right), 6.9(\mathrm{~s}, 8 \mathrm{H}, \mathrm{ArH}) . \mathrm{MS}(\mathrm{m} / \mathrm{z}): 300\left(\mathrm{M}^{+}\right), 272,268,253,239,237,222,211,201,188,183,174$, $166,155,143,120,109,93,82$.

Dibenzo-12-crown-4 (9): 65\% yield; white solids; m.p. = 206-208 ${ }^{\circ} \mathrm{C}$, lit. [19] 208-209 ${ }^{\circ} \mathrm{C}$; IR (KBr): 3000, 2950 , 2850, 1600, 1460, 1320, $950 \mathrm{~cm}^{-1} .{ }^{1} \mathrm{H}$ NMR $\left(\mathrm{CDCl}_{3}, 100 \mathrm{MHz}, \delta \mathrm{ppm}\right): 4.35$ (m, 8H, $\left.\mathrm{CH}_{2} \mathrm{O}\right), 6.85(\mathrm{~m}, 8 \mathrm{H}, \mathrm{ArH})$. MS $(\mathrm{m} / \mathrm{z}): 272\left(\mathrm{M}^{+}\right), 267,252,240,238,226,212,189,182,173,153,121,109,91,80$.

\section{Results and discussion}

The 13-crown-4 (6), 16-crown-5 (7), dibenzo-14-crown-4 (8) and dibenzo-12-crown-4 (9) were synthesized by a one-pot synthetic procedure (Scheme 1). Triethylene glycol (1) or tetraethylene glycol (2) was treated with 1,3dichloropropane (3) in DMSO, using $\mathrm{NaOH}$ as the base, and then irradiated in a microwave oven for $8 \mathrm{~min}$. The macrocyclization was realized in good yields $72 \%$ and $68 \%$, respectively. On the other hand, catechol (5) was treated with 1,3-dichloropropane (3) or 1,2-dichloroethane (4) in the same condition. Interestingly, dibenzo-14-crown-4 (8) and dibenzo-12-crown-4 (9) were obtained in $70 \%$ and $65 \%$ yields, respectively. 


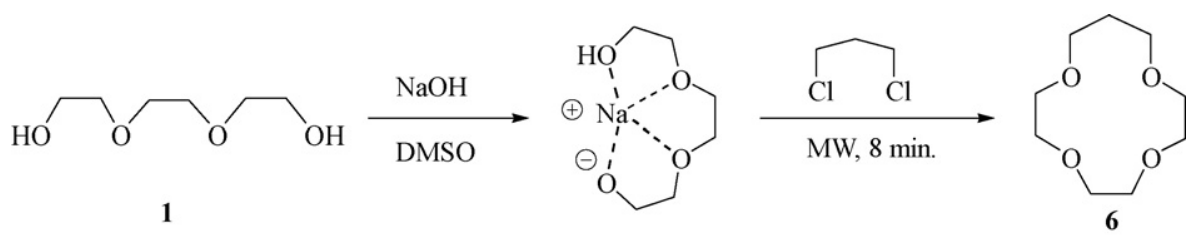

Scheme 2.

The preferred crown- 4 and crown-5 structures may be attributed to the sodium cation template effect in the course of the reactions, as depicted in Scheme 2. The use of $\mathrm{KOH}$ as a base has a similar effects in the cases of compounds 6 and $\mathbf{7}$, but a mixture of products was obtained in each cases of compounds 8 and $\mathbf{9}$.

The structures of products were confirmed by spectral data and melting points were compared with literature. For example, the ${ }^{1} \mathrm{H}$ NMR spectra of $(\mathbf{8})$ in $\mathrm{CDCl}_{3}$ showed a quintet at 2.25 for $\mathrm{CH}_{2}$ group, a triplet at 4.25 for $\mathrm{CH}_{2} \mathrm{O}$ groups, and a singlet at 6.9 for aromatic ring protons. Mass spectrum of the compound showed the molecular ion peak at $\mathrm{m} / \mathrm{z}$ 300. In the IR spectrum the $\mathrm{OH}$ group stretching at $3500 \mathrm{~cm}^{-1}$ disappeared which confirm the macrocyclic structure.

\section{Conclusion}

In conclusion, we have developed a modified Willamson synthesis for the rapid preparation of crown ethers under microwave irradiation in good yields. Irradiation of diols and dichlorides in the presence of sodium hydroxide gave exclusively, title crown ethers without any byproduct formation. We suggested a template effect for this one-pot synthesis.

\section{References}

[1] T.J. Collins, K.L. Kostka, E. Munck, E.S. Uffelman, J. Am. Chem. Soc. 112 (1990) 5637.

[2] E. Kimura, Pure Appl. Chem. 61 (1989) 823.

[3] M. Shamsipur, F. Mizani, M.F. Mousavi, N. Alizadeh, K. Alizadeh, H. Eshghi, H. Karami, Anal. Chim. Acta 589 (2007) 22.

[4] M. Shamsipur, A.R. Fakhari, H. Sharghi, H. Eshghi, M.R. Ganjali, Pol. J. Chem. 76 (2002) 1665.

[5] M. Shamsipur, S. Rouhani, M.R. Ganjali, H. Sharghi, H. Eshghi, Sens. Actuators B 59 (1999) 30.

[6] M. Shamsipur, S. Rouhani, M.R. Ganjali, H. Eshghi, H. Sharghi, Microchem. J. 63 (1999) 202.

[7] M. Shamsipur, S. Rouhani, H. Sharghi, M.R. Ganjali, H. Eshghi, Anal. Chem. 71 (1999) 4938.

[8] B.D. Bubmis, G.E. Paciy, Tetrahedron Lett. 25 (1984) 1107.

[9] M. Hiraoka, Crown Compounds. Their Characteristics and Applications, Elsevier Scientific Publishing Company, New York, 1982.

[10] H. Sharghi, A.R. Massah, H. Eshghi, K. Niknam, J. Org. Chem. 63 (1998) 1455.

[11] H. Sharghi, K. Niknam, M. Pooyan, Tetrahederon 57 (2001) 6057.

[12] (a) J. Smid, Angew. Chem. Int. Ed. Engl. 27 (1972) 1278;

(b) R.J. Katnik, J. Schaefir, J. Org. Chem. 33 (1968) 384.

[13] H. Sharghi, H. Eshghi, Tetrahedron 51 (1995) 913.

[14] H. Eshghi, Synth. Commun. 38 (2008) 2540.

[15] H. Eshghi, M. Mirzaei, H. Esmaily-Shahry, J. Chem. Res. (2007) 272.

[16] M. Ouchi, Y. Inoue, K. Wada, S. Iketani, T. Hakushi, E. Weber, J. Org. Chem. 52 (1987) 2420.

[17] M. Ouchi, Y. Inoue, H. Sakamoto, A. Yamahira, M. Yoshinaga, T. Hakushi, J. Org. Chem. 48 (1983) 3168.

[18] A. Ziafati, O. Sabzevari, M.M. Heravi, Phosphorus Sulfor Silicon 181 (2006) 803.

[19] C.J. Pedersen, J. Am. Chem. Soc. 89 (1967) 7017.

[20] (a) S.V. Ley, I.R. Baxendale, Nat. Rev. 1 (2002) 573;

(b) A. Lew, P.O. Krritzik, M.E. Hart, R. Chamberlin, J. Comb. Chem. 4 (2002) 95.

[21] Y. Liu, Y. Inoue, T. Hakaoushi, Bull. Chem. Soc. Jpn. 63 (1990) 3044. 